may well tempt the clinician to hazard conservative measures, with most serious consequences unless immediate relief is at hand.

\section{Summary of Conclusions}

It may be of service, therefore, to summarize the features of oedema of the glottis complicating measles and to emphasize a few points which may help to distinguish it from laryngeal diphtheria :

Its occurrence may be a feature of certain epidemics, when the incidence is probably under $1 \%$.

The process tends to make its appearance after the rash, most conumonly about 2 days later, although there are instances of its developing as early as the first day and as late as the fifth day.

It is not necessarily associated with a prodromal laryngeal catarrh, although laryngitis was a feature of the epidemic relating to the present series.

Premonitory symptoms are constantly present for a period of 2 to 6 hours. They consist mainly of croupy cough, subdued stridor, slow dyspnoea, and difficulty in swallowing. They are progressive, but, in contradistinction to laryngeal diphtheria. are not concomitantly indicative of the degree of laryngeal occlusion, so that the grave nature of the affection may be overlooked. Once the obstruction becomes marked, fatal asphyxia rapidly ensues, often within 20 minutes. One case, however, recovered spontaneously, and one succumbed after an apparent improvement lasting 24 hours.

In a doubtful case diagnosis may be made by opening the child's mouth and sticking a finger down the throat, when the swollen epiglottis and aryepiglottic folds can be quite easily felt.

Indications of diphtheria will generally be absent; but the possib'e association of faucial disease should not dispose the clinician to temporize if the laryngeal symptoms have made their appearance within the few days following the eruption and present the above-mentioned characteristic features.

The mortality in untreated cases is probably not far short of $100 \%$. Thus, in 8 cases of the present series there was only one spontaneous recovery, and in 10 other undoubted cases there were none.

Oedema of the glottis complicating measles is not an academic curiosity but a vital entity which mav confront the practitioner at any time during an outbreak of the disease.

\section{Medical Memoranda}

\section{Full-term Extra-uterine Pregnancy with Living Ghild}

For the sake of record and to emphasize a method of treatment, I have been urged to write this case report and to refer briefly to three others.

\section{CASE Record}

The patient, a 7-para aged 39, was admitted to Mackay Memorial Hospital, Taihoku, Formosa, on March 1, 1931, in an exhausted condition, with a history of "having been in labour" three days. The radial pulse could not be felt. The pulse was 55 , respiration 38 , temperature $35.2^{\circ} \mathrm{C}$. $\left(95.4^{\circ} \mathrm{F}\right.$.). There was a history of severe abdominal pain for three days, with blood discharge from the vagina; she was constipated during this period. The movements of the child could still be felt by the mother. The last menstrual period had occurred from April 13 to 15, 1930. In June and in September she had had attacks of abdominal pain which kept her in bed a few days, and according to the husband there was no vaginal bleeding at these times. From January 5 to 15,1931 , and from February 27 to March 1 she had had further attacks of pain which doubled her up, the pain at the final attack being the most severe of all. On vaginal examination the cervix could not be felt; by abdominal examination the foetal parts were unusually easily palpated and seemed to be just under the skin. A diagnosis of full-term extra-uterine pregnancy was made and immediate laparotomy undertaken.

The secondary gestation sac was filled with a greenishyellow fluid and had adherent omentum and gut over a wide area. The cord was ligated and divided, and the child delivered. The placenta was firmly adherent to the left side of the posterior wall of the abdomen, extending down to the uterus, which could be felt drawn up and to the left, small and firm; the placenta was also adherent to the small gut, which was distended, red, and velvety. There was no haemorrhage in the sac or in the peritoneal cavity. The patient died fifteen hours later from ileus and shock. As there was no time to investigate the exact relations of placenta and uterus at the operation, the husband gave permission for a limited post-mortem examination on condition of his being present. This was carried out in the operating theatre, and the following is a copy of my notes made at the time: "Postmortem examination 10.20 a.m. in operating theatre, husband and his sister present. Operation wound opened up; there was no blood in the sac or in the peritoneal cavity. Placenta adherent and involved the left side of abdomen and left side of uterine fundus; could not palpate adnexa of right side. Without further cutting could not free placenta or see pelvic contents. Husband, a very sane man, considering we had found out what was necessary, did not want her cut any further."

The child was a well-formed healthy girl weighing over $7 \mathrm{lb}$. (the chart did not record the weight, but $I$ have distinct memory of her being well over normal weight). Her subsequent history showed that she was not only a beautiful normal child but above the average in intelligence. As the husband considered she had been the cause of the mother's death he did not want the infant, and she was offered to me for adoption. One of my native nurses adopted her by paying the sum of one yen. The child was still alive and well in November, 1940, when I left the district.

From the end of the patient's last menstrual period till the day of delivery was $\mathbf{3 2 0}$ days. It would be interesting to know just how long, under these circumstances, a child could live. It is evident that this one was near the end of active life, as when removed from the mother it did not at once show signs of life ; but while I was still attending the mother the infant started to cry.

\section{Other CASEs}

In 1914, in Tainan, Formosa, I had a case of full-term extrauterine pregnancy in a woman aged 42 . This case was reported in the China Medical Journal, 1915, 29, 14, from which I quote: "Child removed from its bed with as much of the surrounding sac as could safely be taken away, then the margins of the sac were stitched to the abdominal opening and the cavity packed with two towels. The towel was adherent all around the sac. Patient ran a septic temperature from $97^{\circ}$ to $103^{\circ} \mathrm{F}$. for thirty-seven days, after which the temperature remained normal and she made an uninterrupted recovery. Seen five months after operation the wound had quite healed, and her only discomfort was pain on menstruating. ... The child (dead) weighed $7 \mathrm{lb}$. and was well formed."

In 1934, in Taihoku, in one ward at the same time were two cases of extra-uterine gestation ruptured in the earlier months; and two full-term extra-uterine cases, ages 38 and 40 , each with dead child. All four patients recovered. The treatment in each full-term case was the same: the placenta was undisturbed, cavity lightly packed, and neither gave any further anxietythis in contrast to the method of immediate removal of the placenta, when "the immediate after-treatment of such cases is always an anxious matter" (Whitehouse, 1935). One of these patients was running a septic temperature on admission, and her wound healed two or three weeks before the other nonfebrile case. In none of these last three cases was there any haemorrhage in the sac or peritoneal cavity.

The point in treatment I wish to make is that by marsupialization and allowing the placenta to disintegrate and come away gradually, without over-zealous use of forceps and scissors, even with the risk of sepsis and secondary haemorrnage, the total risks involved are fewer than when an attempt is made to remove the placenta at once, which may be met by "formidable technical difficulty" and " haemorrhage of the most severe kind ... very difficult to control" (Whitehouse, 1935).

G. Gushue-TAYLOR, M.B., B.S., F.R.C.S.,

Late Superintendent. Canadian Presbyterian Mirsion Hospital

Director, Happy Mount Leprosy Colony, Formosa, Japan.

\section{REFERENCE}

Whitehouse, H. Beckwith (1935). In Eden and Lcckyer's Gynaecology, 4th ed, p. 252, Churchill. 